LA-14381

Approved for public release;

distribution is unlimited.

Targeted and Comprehensive Space-Environment Sensors: Description and Recommendations 
Edited by Mable Amador, Group IRM-CAS.

Photocomposition by Deidre' A. Plumlee, Group IRM-CAS.

Los Alamos National Laboratory, an affirmative action/ equal opportunity employer, is operated by Los Alamos National Security, LLC, for the National Nuclear Security Administration of the U.S. Department of Energy under contract DE-AC52-06NA25396.

This report was prepared as an account of work sponsored by an agency of the U.S. Government. Neither Los Alamos National Security, LLC, the U.S. Government nor any agency thereof, nor any of their employees make any warranty, express or implied, or assume any legal liability or responsibility for the accuracy, completeness, or usefulness of any information, apparatus, product, or process disclosed, or represent that its use would not infringe privately owned rights. Reference herein to any specific commercial product, process, or service by trade name, trademark, manufacturer, or otherwise does not necessarily constitute or imply its endorsement, recommendation, or favoring by Los Alamos National Security, LLC, the U.S. Government, or any agency thereof. The views and opinions of authors expressed herein do not necessarily state or reflect those of Los Alamos National Security, LLC, the U.S. Government, or any agency thereof. Los Alamos National Laboratory strongly supports academic freedom and a researcher's right to publish; as an institution, however, the Laboratory does not endorse the viewpoint of a publication or guarantee its technical correctness. 
LA-14381

Issued: January 2009

\section{Targeted and Comprehensive Space-Environment}

\section{Sensors: Description and Recommendations}

Geoffrey Reeves

Paul O’Brien*

Joe Mazur*

Gregory Ginet**

* Space Sciences Department/Chantilly, The Aerospace Corporation, Greens III, 2080, 15049 Conference Center Drive, CH3/210, Chantilly, VA 20151-3824

** AFRL/VSBX, 29 Randolph Rd., Hanscom AFB, MA 01731

\section{Los Alamos}


This page left blank intentionally. 


\title{
Targeted and Comprehensive Space-Environment Sensors: Description and Recommendations
}

\author{
by \\ Geoffrey Reeves, Los Alamos National Laboratory \\ Paul O'Brien and Joe Mazur, The Aerospace Corporation \\ Gregory Ginet, Air Force Research Laboratory
}

\begin{abstract}
We discuss the roles of the two classes of space-environment sensors on operational space systems: (1) Targeted sensors capable of measuring the environment and effects at a level sufficient for providing situational awareness for the host spacecraft and (2) Comprehensive sensors capable of providing detailed environment measurements that can be mapped to a broad region of near-Earth space, providing global situational awareness and quantitative characterization of the environment. Our purpose is to show the usefulness of a heterogeneous architecture with both classes of sensors for the near-term and long-term needs of National Security Space.
\end{abstract}

\section{INTRODUCTION}

Energetic particles and plasma in the space environment can be hazardous to space systems, causing system outages, shortening mission lifetimes, reducing functional capabilities, and potentially masking hostile actions. Effects include the degradation of electronic components resulting from total ionizing dose and dose rate, arcing between surfaces induced by warm plasma, electrical breakdown of dielectric materials caused by energetic electrons, and corrupted data and spurious commands driven by energetic ions through single-event effects. Table 1 summarizes the space-environment hazards and the responsible particle populations that are the background of this paper.

Table 1. Space-Environment Hazards

\begin{tabular}{|l|l|l|}
\hline Environmental Hazard & Particle Population & Particle Dynamics Timescale \\
\hline Surface Charging & $0.01-100 \mathrm{keV} \mathrm{e}^{-}$ & Minutes \\
\hline Surface Dose & $0.5-100 \mathrm{keV} \mathrm{e}^{-}, \mathrm{H}^{+}, \mathrm{O}^{+}$ & Minutes \\
\hline Internal Charging & $100 \mathrm{keV}-10 \mathrm{MeV} \mathrm{e}^{-}$ & Hours \\
\hline Total Ionizing Dose & $>100 \mathrm{keV} \mathrm{H}, \mathrm{e}^{-}$ & Hours \\
\hline Single Event Effects & $>10 \mathrm{MeV} / \mathrm{amu} \mathrm{H}^{+}$, Heavy ions & Days \\
\hline Displacement Damage & $>10 \mathrm{MeV} \mathrm{H}^{+}$, Secondary neutrons & Days \\
\hline Nuclear Activation & $>50 \mathrm{MeV} \mathrm{H}^{+}$, Secondary neutrons & Weeks \\
\hline
\end{tabular}

We classify the sensors that have been used to measure these space environments and their effects on operational vehicles into two broad categories: (1) Targeted sensors that are capable of measuring the environment and effects at a level sufficient for providing situational awareness of specific effects for the host spacecraft and (2) Comprehensive sensors that are capable of providing detailed environment measurements for a wide variety of effects and to map those 
measurements to a broad region of near-Earth space, providing global situational awareness and quantitative characterization of the environment climatology for the design of future space systems. Table 2 lists several examples of each sensor type that have been flown or are manifest for flight.

Our general classification refers to the primary mission of the sensor. We recognize that there are cases in which other uses of the sensor data might blur the distinction between Targeted and Comprehensive. For example, Comprehensive sensors typically provide situational awareness for the host vehicle as well as comprehensive measurements that can be mapped to a larger volume of space. Likewise, the data returned from Targeted sensors hosted on many vehicles has been used for global space situational awareness through integration into assimilative environment models and for validation of climatology models needed for spacecraft design.

Table 2. Examples of Space-Environment Sensors for Operational Vehicles

\begin{tabular}{|c|c|c|c|c|c|c|c|c|}
\hline $\begin{array}{c}\text { Sensor } \\
\text { Name }\end{array}$ & Type $^{1}$ & $\begin{array}{c}\text { Mass } \\
(\mathbf{k g})\end{array}$ & $\begin{array}{c}\text { Telemetry } \\
\text { Rate } \\
\text { (bits/s) }\end{array}$ & Platform(s) & Orbit & Hazards & Provider & Ref. \\
\hline $\begin{array}{l}\text { CEASE } \\
\text { CEASE-II }\end{array}$ & $\mathrm{T}$ & 1.0 & 1.3 & $\begin{array}{l}\text { TSX-5 } \\
\text { DSP-21 }\end{array}$ & $\begin{array}{l}\text { LEO } \\
\text { GEO }\end{array}$ & $\begin{array}{l}\text { Dose, } \\
\text { Charging, SEE }\end{array}$ & AFRL & $\begin{array}{l}\mathrm{Di} 98 \\
\text { Co04 }\end{array}$ \\
\hline $\begin{array}{l}\text { BDD } \\
\text { CXD }\end{array}$ & $\mathrm{T}$ & $\begin{array}{l}6.8 \\
3.5 \\
\end{array}$ & 0.5 & GPS & MEO & $\begin{array}{l}\text { Dose, Dose } \\
\text { Rate, SEE }\end{array}$ & LANL & $\begin{array}{l}\mathrm{Ca} 98 \\
\mathrm{Tu} 04 \\
\end{array}$ \\
\hline CPA & $\mathrm{T}$ & 0.15 & 10 & Intelsat & GEO & Charging & $\begin{array}{l}\text { Lockheed } \\
\text { Martin }\end{array}$ & $\begin{array}{l}\text { Bo95 } \\
\text { Ta07 } \\
\end{array}$ \\
\hline Merlin & $\mathrm{T}$ & 1.0 & & Giove-A & MEO & $\begin{array}{l}\text { Dose, } \\
\text { Charging, SEE }\end{array}$ & Qinetiq & \\
\hline $\begin{array}{l}\text { ADS02 } \\
\text { chip } \\
\text { dosimeter }\end{array}$ & $\mathrm{T}$ & 0.02 & 0.13 & $\begin{array}{l}\text { LRO } \\
\text { (launch } \\
\text { Nov 2008) }\end{array}$ & Lunar & Total Dose & Aerospace & $\mathrm{Ma07}$ \\
\hline $\begin{array}{l}\text { DOS+ } \\
\text { SCM+ } \\
\text { HILET }\end{array}$ & $\mathrm{C}$ & \begin{tabular}{|c|}
8.9 \\
total mass
\end{tabular} & 45,000 & $\begin{array}{l}\text { Classified } \\
\text { platform }\end{array}$ & HEO & $\begin{array}{l}\text { Dose, } \\
\text { Charging, SEE }\end{array}$ & Aerospace & $\mathrm{Ma} 04$ \\
\hline SEM & $\mathrm{C}$ & 15.0 & 96 & NOAA/POES & LEO & $\begin{array}{l}\text { Dose, } \\
\text { Charging, SEE }\end{array}$ & NOAA & \\
\hline SEM & $\mathrm{C}$ & & $\sim 0.5$ & $\begin{array}{l}\text { NOAA/GOE } \\
\mathrm{S}\end{array}$ & GEO & $\begin{array}{l}\text { Dose, } \\
\text { Charging, SEE }\end{array}$ & NOAA & An96 \\
\hline $\begin{array}{l}\mathrm{CPA}+\mathrm{SEE} \\
\mathrm{MPA}+\mathrm{SO} \\
\mathrm{PA}+\mathrm{ESP}\end{array}$ & $\mathrm{C}$ & $\begin{array}{c}3.5 \\
\text { per box }\end{array}$ & $\begin{array}{c}1,500 \\
\text { per box }\end{array}$ & LANL & GEO & $\begin{array}{l}\text { Dose, } \\
\text { Charging, SEE }\end{array}$ & LANL & $\begin{array}{l}\text { Mc93; } \\
\text { Me96 } \\
\text { Be92 }\end{array}$ \\
\hline SSJ4/5 & $\mathrm{C}$ & 3.2 & 360 & DMSP & LEO & Charging & AFRL & SC88 \\
\hline $\begin{array}{l}\text { SABRS } \\
\text { ZEP+ZPS }\end{array}$ & $\mathrm{C}$ & \begin{tabular}{|l|}
$\sim 9$ \\
total mass
\end{tabular} & $\begin{array}{l}\text { Up to } \\
20 \mathrm{kbps}\end{array}$ & Various & Various & \begin{tabular}{|l|} 
Dose, \\
Charging, SEE \\
\end{tabular} & LANL & \\
\hline
\end{tabular}

Notes:

1. $\mathrm{T}=$ Targeted $\mathbf{C}=$ Comprehensive.

More detailed information on a subset of the sensors in Table 2 and examples of their on-orbit utility are provided below. 


\section{Targeted Space Weather and Effects Sensors}

Targeted sensors measure space-environment hazards to the host vehicle with a focus on a specific effect or set of effects (e.g., dose, single event effects, etc.). In some cases, information about the details of the particle environment (e.g., energy spectrum; angular dependence) outside the vehicle can be derived after the fact. However, the primary benefit of targeted data, such as the total accumulated dose, or the instantaneous potential of a surface relative to the spacecraft frame, is for the situational awareness and health and safety of the host vehicle.

\section{CEASE}

Successful operation of the Compact Environment Anomaly Sensor (CEASE) has demonstrated the utility of small on-board space weather sensors. CEASE is a $10 \mathrm{~cm} \times 10 \mathrm{~cm} \times 8.2 \mathrm{~cm}, 1 \mathrm{~kg}$, and 1.5 Watt box made up of five separate sensors capable of measuring a wide range of the energetic particles responsible for spacecraft hazards [Di98]. Successful test flights of CEASE on the low-Earth orbiting Space Test Program satellite Tri-Service Experiment Satellite \#5 (TSX-5) and CEASE-II (an upgraded version of CEASE) on the geosynchronous orbiting Defense Support Program satellite DSP-21 have validated performance through more than seven years of combined operation. Several anomalies on TSX-5 were resolved quickly using CEASE data [Di01]. CEASE-II on DSP-21 was an Advanced Technology Demonstration (ACTD). As a result of a Military Utility Analysis conducted as part of the ACTD, Air Force Space Command (AFSPC) recommended to the United States Strategic Command (USSTRATCOM) that they "support CEASE-II requirement on all future spacecraft." [Co04].

\section{$C X D / B D D$}

Some targeted sensors are routinely flown on all satellites in a system. An example is the Global Positioning Satellite (GPS) constellation. Initially targeted Burst Detector-Dosimeter (BDD) instruments were flown on at least one satellite in each of the six GPS orbital planes with operational X-ray sensors on the remaining spacecraft. With improvements in instrument design and greater understanding of the GPS environment, a new generation of Combined $\mathrm{X}$-ray/Dosimeter (CXD) instruments was developed. CXD performance exceeds BDD performance considerably while using fewer than half the resources, thus enabling combining X-ray and Dosimeter functions into a single instrument and the ability to provide both functions to every vehicle in the constellation with no additional impact on the host vehicle.

\section{CPA}

Developments in even more targeted, lower-impact sensors can provide information on specific space weather effects without necessarily measuring or analyzing the populations that cause them. An excellent example of a space weather effects sensor is the Charged Plate Analyzer (CPA) flown on several commercial satellites [Bo95; Oz01]. This simple sensor provides a real-time estimate of surface charging occurring on a surface patch representative of the host vehicle. Although it is not possible to deduce the incident particle radiation environment from such a sensor, the CPA's output is simple to understand and process automatically. A high CPA voltage is a straightforward indication that the vehicle is at risk of surface charging, which can lead to electrostatic discharge and various negative consequences thereof. 


\section{ADS02 (Chip Dosimeter)}

Research programs are underway at Aerospace and Air Force Research Laboratory (AFRL) to further decrease the size and resource requirements of dose and charging effects sensors to levels well below CEASE-class sizes, i.e., to the level of "thermistors" where they ultimately become part of the bus infrastructure [Ma07]. A sacrifice in measurement resolution and dynamic range will be offset by the large number of sensors possible at a multitude of critical spacecraft locations and by leveraging the measurements from comprehensive sensors on a much smaller subset of platforms that enable global context and on-orbit cross-calibration of instrument responses.

\section{Comprehensive Sensors for Weather, Effects, and Climatology}

Comprehensive sensors also make measurements of one or more space-environment hazards but return detailed energy and angular resolution with a large dynamic range; the corresponding resource requirements are naturally larger than Targeted sensors (see Table 2). Typically, more comprehensive measurements are needed when the space weather effects on a particular host are not well understood or their causes are not known; when it is necessary to mitigate space weather effects such as background signals in space instruments; or when there is a need to extend the data to locations far from the host spacecraft through mapping of particle distributions in magnetic coordinates with a fair degree of accuracy. Thus, a single point measurement specifies a relatively large volume of the radiation environment at a broad range of energies.

\section{GEO sensors: NOAA and LANL}

Well-known examples of comprehensive space-environment sensors are the Geostationary Operational Environmental Satellite (GOES) and Los Alamos National Laboratory (LANL) particle sensors at Geosynchronous Orbit (GEO) [An96; Mc93; Be92; Me96]. Combined, these two constellations provide long-term measurements of the proton and electron environment for particles with energies from a few $\mathrm{eV}$ to hundreds of $\mathrm{MeV}$. As a result, the geosynchronous environment is one of the best characterized for spacecraft design [e.g., Bo03, Si06].

\section{LEO Sensors: NOAA TIROS and POES}

Another well-known example of long-term space-environment sensors is the particle instruments on the NOAA TIROS or Polar Operational Environmental Satellite (POES) constellation, in sun-synchronous orbit at $\sim 800 \mathrm{~km}$. Although not as comprehensive as the GEO measurements, the POES/SEM package includes a set of proton measurements that have been used to quantify the long-term variability of the energetic protons in Low-Earth Orbit (LEO), including the motion of the South Atlantic Anomaly, a region of intense radiation in LEO [Hu02].

Orbital environments other than GEO and LEO/Sun-Synch are poorly monitored, leading to large uncertainties in anomaly assessment and spacecraft design specifications. A successful strategy for deploying comprehensive sensors would provide similar coverage for other widely used orbits while also preparing at least preliminary climatology information for arbitrary new orbits. 


\section{Roles of Targeted and Comprehensive Sensors}

\section{Targeted Sensors}

Low-impact and inexpensive space weather sensors should be placed on all operational spacecraft to provide situational awareness for improved operations, rapid and accurate anomaly assessment, and, when integrated over constellations or fleets, to provide a global picture of the space-environment threat. An optimal space situational awareness package should contain monitors for directly measuring the environmental effects relevant to satellite subsystems, including dose deposition, single-event effect rates, surface charging, and internal charging. Without space weather sensors on a vehicle, the mission must rely on various interpolations and extrapolations in order to assess the environment hazard during operations or during an anomaly resolution. Currently, such extrapolated environmental specifications are time consuming to produce, inaccurate and of a low confidence level, although numerical tools are actively under development to enable future more-accurate mapping of local measurements to a global environment specification. Real-time, spatially accurate space-environment data from a targeted sensor are critical to determining whether a specific anomaly event might be the result of hostile activity rather than natural phenomena.

Targeted sensors will also provide databases that can be used to correlate environments with anomalous events and continuous degradation to improve satellite design ultimately enhancing capability while reducing acquisition and operations costs. Although there is as yet no mandate or central authority to guide the acquisition of such sensors (although a space-environment and effects-sensing requirements document is in draft at the Air Force Space Command), there is a growing consensus in the satellite operations and acquisition community that new technologies, new orbits, and new threats will continue to expand the need for space-environment sensors.

\section{Comprehensive Sensors}

When integrated with data-assimilation algorithms, a small number of comprehensive sensors could provide global situational awareness throughout the entire near-Earth space regime. Resolution and utility will be further improved as better tools are developed to process targeted space weather sensors to levels that can be incorporated in data-assimilation models. As sensors proliferate, the assimilation of data can provide a global picture of the space-environment threat to all blue, red, or grey forces with the accuracy of the threat assessment in proportion to the number and distribution of sensors.

Comprehensive space-environment data also provide the long-term description of the average environment and its variation (space climatology). This type of information is critical for improving radiation design specifications, such as AE-8 and AP-8 [Ve91; Sa76]. Because the Solar Cycle has an 11-year activity cycle (22-year magnetic) and varies considerably in dynamic range, long-term measurements are essential. For example, the author of the standard AE and AP specification models remarked, "the inclusion of newer data at regular intervals is mandatory because our knowledge of the radiation belts increases as improved instruments are flown and new ideas are advanced" [Ve66]. In order to enable updates of the radiation specifications, comprehensive sensors should be flown in every critical, commonly used orbit (e.g., GEO, Highly Elliptical Orbit [HEO]/Molniya, Medium Earth Orbit [MEO] and LEO) and on path-finder missions. In addition, comprehensive sensors can be of high value when flown on 
elliptical orbits, especially those with low inclination (e.g., Geosynchronous Transfer Orbit [GTO]).

\section{SUMMARY}

Individual satellite programs reap the benefits from enhanced situational awareness and reduced anomaly resolution time as a result of having space weather effects sensors on all of their assets. All of National Security Space benefits from comprehensive sensors through better situational awareness at points far away from the sensor platform and from the detailed climatology data gathered over long-duration missions.

\section{ACKNOWLEDGEMENTS}

The authors acknowledge contributions from: LTC Clark Groves (USAF); Michelle Thomsen, Marc Kippen, and Eric Dors (LANL); and James Clemmons (The Aerospace Corporation). ATR-2008(8073)-4.

\section{REFERENCES}

An96 Anon, GOES I-M Databook, rev.1, Space Systems-Loral, (August, 1996).

Be92 Belian, R.D., G.R. Gisler, T.E. Cayton, and R. Christensen, "High Z Energetic Particles at Geosynchronous Orbit during the Great Solar Proton Event of October," 1989, J. Geophys. Res. 97, 16,897 (1992).

Bo95 Bogorad, A., et al., "Integrated Environmental Monitoring System for Spacecraft." IEEE Trans. Nucl. Sci. 42(6), 2,051-2,057, 1995.

Bo03 Boscher, D.M., S.A. Bourdarie, R.H.W. Friedel, and R.D. Belian, "Model for the Geostationary Electron Environment: POLE," IEEE Trans. Nucl. Sci. 50(6), 2,278 (2003).

Ca98 Cayton, T.E., D.M. Drake, K.M. Spencer, M. Herrin, T.J. Wehner, and R.C. Reedy, "Description of the BDD-IIR: Electron and Proton Sensors on the GPS," Los Alamos National Laboratory document LA-UR-98-1162 (1988).

Co04 "Compact Environment Anomaly Sensor II Advanced Concept Technology Demonstration Final Report," Space Warfare Center, Schriever AFB, CO, (2003). Final report signed, June 16, 2004.

Di98 Dichter, B.K., J.O. McGarity, M.R. Oberhardt, V.T. Jordanov, D.J. Sperry, A.C. Huber, J.A. Pantazis, E.G., Mullen, G.P. Ginet and M.S. Gussenhoven, "Compact Environmental Anomaly Sensor (CEASE): A Novel Spacecraft Instrument for In Situ Measurement of Environmental Conditions," IEEE Trans. Nucl. Sci. 45, No. 6: 2,758 (1998).

Di01 Dichter, B.K., W.R. Turnbull, D.H. Brautigam, K.P. Ray, and R.H. Redus, "Initial On-Orbit Results from the Compact Environmental Anomaly Sensor (CEASE)," IEEE Trans. Nucl. Sci. 48, 2,022-2,028 (2001).

Hu02 Huston, S.L., "Space Environment and Effects: Trapped Proton Model," NASA/CR-2002-211784, NASA Marshall Spaceflight Center. Huntsville, AL (2002).

Ma04 Mazur, J.E., W.R. Crain, C.N. Camacho, A.Y. Lin, D. Mabry, M. van Dyke, E. Pierre-Louis, and M. Papadopolous, "Dose/Surface Charging and Plasma Monitor 
(DOS/SCM) Flight Model 2-HiLET Subsystem Critical Design Review," Aerospace Report TR-2004(8570)-2 (2004).

Ma07 Mabry, D., Advanced Dosimeter System, The Aerospace Corporation, P/N ADS02, Rev. 2, (March 2007).

Mc93 McComas, D.J., S.J. Bame, B.L. Barraclough, J.R. Donart, R.C. Elphic, J.T. Gosling, M.B. Moldwin, K.R. Moore, and M.F. Thomsen, "Magnetospheric Plasma Analyzer (MPA): Initial Three-Spacecraft Observations from Geosynchronous Orbit," J. Geophys. Res. 98, 13,453 (1993).

Me96 Meier, M.M., R.D. Belian, T.E. Cayton, R.A. Christensen, B. Garcia, K.M. Grace, J.C. Ingraham, J.G. Laros, and G.D. Reeves, "The Energy Spectrometer for Particles (ESP): Instrument Description and Orbital Performance," in Workshop on the Earth's Trapped Particle Environment, edited by G.D. Reeves, AIP Press, New York, 203-210 (1996).

Oz01 Ozkul, A., et al., "Initial Correlation Results of Charge Sensor Data from Six INTELSAT VIII Class Satellites with Other Space and Ground-Based Measurements," Proceedings of the 7th Spacecraft Charging Technology Conference, SP-476, ESA, Noordwijk, The Netherlands, 293-298, 2001.

Sa76 Sawyer, D.M., and J.I. Vette, "AP-8 Trapped Proton Model, NSSDC/WDC-A-R\&S 76-06," National Space Science Data Center, Greenbelt, MD (1976).

Sc88 Schumaker, T.L., D.A. Hardy, S. Moran, A. Huber, J. McGarity, and J. Pantazis, "Precipitating Ion and Electron Detectors (SSJ/4) for the Block 5D/Flight 8 DMSP Satellite," AFGL-TR-88-0030, Air Force Research Laboratory, Hanscom AFB, MA (1988).

Si06 Sicard Piet, A., S. Bourdarie, D. Boscher, and R.H.W. Friedel, "A Model for the Geostationary Electron Environment: POLE, from $30 \mathrm{keV}$ to $5.3 \mathrm{MeV}$," IEEE Trans. Nucl. Sci. 53(4), 1,844 (2006).

Ta07 Taylor, B., et al., "Results From the Galileo Giove-A Radiation Monitors and Comparison With Existing Radiation Belt Models," IEEE Trans. Nucl. Sci. 54, 4 (2007).

Tu04 Tuszewski, M., T.E. Cayton, J.C. Ingraham, and R.M. Kippen, "Bremsstrahlung Effects in Energetic Particle Detectors," Space Weather 2, S10S01, doi:10.1029/2003SW000057 (2004).

Ve91 Vette, J.I., "The AE-8 Trapped Electron Model Environment, NSSDC/WDC-A-R\&S 91-24," NASA Goddard Space Flight Center, Greenbelt, MD (1991).

Ve66 Vette, J.I., "Models of the Trapped Radiation Environment, Volume I: Inner Zone Protons and Electrons," NASA SP-3024 (1966). 


\section{APPENDIX: ACRONYMS}

ACTD Advanced Technology Demonstration

AFRL Air Force Research Laboratory

BDD Burst Detector Dosimeter

CEASE Compact Environment Anomaly Sensor

CPA Charge Plate Analyzer (Intelsat surface charging monitor)

CPA Charged Particle Analyzer (LANL energetic particle sensor at GEO)

CXD Combined X-Ray sensor and Dosimeter

DMSP Defense Meteorological Satellite Program (DoD weather satellite).

DoD Department of Defense

DOS Dosimeter

DSP-21 Defense Support Program satellite \#21 (DoD operational satellite).

ESP Energy Spectrometer for Particles

GEO Geosynchronous Orbit

GOES Geostationary Operational Environmental Satellite (NOAA weather satellite).

GPS Global Positioning Satellite

GTO Geosynchronous Transfer Orbit

HEO Highly Elliptical Orbit (classified satellite)

HILET High Linear Energy Transfer

LANL Los Alamos National Laboratory.

LEO Low-Earth Orbit

MEO Medium Earth Orbit

MPA Magnetospheric Plasma Analyzer

NOAA National Oceanic and Atmospheric Administration

POES Polar Operational Environmental Satellite (NOAA weather satellite)

SABRS Space and Atmospheric Burst Recording System

SCM Surface Charge Monitor

SEE Spectrometer for Energetic Electrons (LANL instrument at GEO)

SEE Single Event Effects (space-environment hazard)

SEM Space Environment Monitor.

SOPA Synchronous Orbit Particle Analyzer

SSJ5/4 Special Sensor J4 or J5.

TSX-5 Tri-Service Experiment satellite \#5 (DoD experimental satellite).

USAF United States Air Force

USSTRATCOM United States Strategic Command

ZEP SABRS Energetic Particle (LANL energetic particle sensor at GEO)

ZPS SABRS Plasma Spectrometer (LANL plasma sensor at GEO) 
This page left blank intentionally. 
This page left blank intentionally. 
This report has been reproduced directly from the best available copy. It is available electronically on the Web (http://www.doe.gov/bridge).

Copies are available for sale to U.S. Department of Energy employees and contractors from:

Office of Scientific and Technical Information

P.O. Box 62

Oak Ridge, TN 37831

(865) 576-8401

Copies are available for sale to the public from: National Technical Information Service

U.S. Department of Commerce

5285 Port Royal Road

Springfield, VA 22161

(800) 553-6847 
- Los Alamos NATIONAL LABORATORY

EST.1943 